Bangl. J. Vet. Med. (2006). 4 (1): 01-06

\title{
A SHORT HISTORY OF BRUCELLOSIS: SPECIAL EMPHASIS IN BANGLADESH
}

\author{
M. S. Rahman, M. J. Uddin, Jin-ho Park ${ }^{1}$, Joon-seok Chae ${ }^{1}$, M. B. Rahman ${ }^{2}$ and M. A. Islam
}

Department of Medicine, Faculty of Veterinary Science, Bangladesh Agricultural University, Mymensingh2202, Bangladesh, ${ }^{1}$ Bio-saferty Research Institute and College of Veterinary Medicine, Chonbuk National University, Jeonju 561-756, South Korea, ${ }^{2}$ Department of Microbiology and Hygiene, Faculty of Veterinary Science, Bangladesh Agricultural University, Mymensingh-2202, Bangladesh, ${ }^{3}$ Department of Paediatrics, Rajshahi Medical College, Rajshahi University, Rajshahi, Bangladesh

\section{INTRODUCTION}

Brucellosis is an important disease caused by gram- negative bacteria Brucella that are pathogenic for a wide variety of animals and human. The disease is also called 'Malta fever', 'Mediterranean fever or undulant fever'. The main domestic animals that are affected are cattle, sheep, goats, and pigs (Moore and Schnurrenberger, 1981; Young, 1995; OIE, 2000). The principal manifestations of animal brucellosis are reproductive failure, i.e, abortion and birth of unthrifty offspring in females, and orchitis and epididymitis in males. Brucellosis in human being is usually characteristics by influenza like clinical disease, which may be severe and may be followed by chronic intermittent relapses (Hugh-Jones, 2000).

The genus Brucella has six recognized species on the basis of host specificity. Among all six species of Brucella, the greatest economic impact results from bovine brucellosis caused by $B$. abortus. Brucellosis in cattle is usually caused by biovars of $B$. abortus. In some countries, particularly in southern Europe and Western Asia, where cattle are kept in close association with sheep or goats, infection can also be caused by B. melitensis (OIE, 2000).

The history of brucellosis does not begin with the isolation and identification of Brucella melitensis (Micrococcus melitensis) in the 1880s. Many historical accounts of diseases before this time could actually be describing brucellosis including abortion epidemics in animals and fever in humans. Other than biblical references to animal abortions, one of the earliest recorded descriptions of brucellosis was made by Marston in 1859 (Vassalo, 1992). He wrote of an illness, including of his own, which differed from typhoid fever. There are other recordings of how, what is now believed to have been brucellosis, disease affected the Crimean War and sailors aboard ships. Brucellosis then called Mediterranean fever and was a debilitating chronic illness with the complication of rheumatism for which many Royal Naval seaman were invalidated each year (Wyatt, 1999).

Captain David Bruce was sent to Malta and, with several others, conducted research from 1884. He isolated an agent called Micrococcus melitensis from human spleens. Hospitalized patients were fed raw goat's milk for many illnesses giving an early example of nosocomial infections. A Mediterranean Fever Commission was formed in 1905 and Bruce was named chairman. The early workers were convinced that brucellosis was vector borne. A shortage of monkeys for research on brucellosis led to the use of goats. It was believed that goats were no affected since they did not become ill when inoculated with cultures. Themistocles Zammit, a physician and only Maltese member of the commission, was known more from his archeology. He tested the blood of goats and found that as many as $50 \%$ had agglutinins. He and other workers isolated the bacteria from blood and milk of at least $10 \%$ goats. Much controversy arose over who should be given credit for the discovery of the role of goats in brucellosis. When the Mediterranean Fever Commission suggested that the goat was responsible for human illness, it initiated a vigorous correspondence in local newspapers and international journals. The latter verse refers to a ship, the S.S. Joshua Nicholoson when anchored at Malta in 1905 took on board 65 goats bound for Washington. The Bureau of Animal Industry (BAI) of the USDA had decided to import Maltese goats to encourage goat husbandry among peasant immigrants from southern Europe. Nearly all the ship's crews drank the raw milk and within weeks, were ill. The goats were never shipped to the United States on the recommendation of Bruce. 
Goat's milk was banded from the military garrison in 1906 but the controversy about the goat persisted for many years. The goat had a special niche in Maltese culture and was taken door to door for fresh milk. A pasteurization commission was formed in 1938 but it was not until 1959 that the ban was enforced. Even as late as 1955, over 200 human cases of brucellosis were caused by ingestion of a special cheese (soft cheese). In 1964, the only two postage stamps in the world referring to brucellosis were issued in Malta to honor Bruce and Zammit.

Professor L. F. Benhard Bang, Danish veterinary pathologist and bacteriologist, described a different causative organism in cattle in 1895 called Bacillus abortus. And in 1914 in the United States, a Brucella species was isolated from an aborted pig fetus and named B. suis. The description of isolates from cattle and swine led to a recognition of widespread distribution in other countries.

The first recognized human case of brucellosis in the United States was in 1898 in an army officer who contracted the disease in Puerto Rico (Brown, 1977). In the continental United States, cases occurred in Texas, New Mexico and Arizona caused by B. melitensis. However, goats have never been a major industry and interest was low. Interest was high in cattle in the early part of the 20th century as contagious abortion was recognized along with tuberculosis as a serious cause of economic losses. The BAI played a dominant role in research on bovine and procine brucellosis and development of an eradication program. Research was active on diagnostic tests and on immunizing agents and methods. Many possible treatment compounds and regimens were claimed. Various committees and organizations considered the name of the disease, research topics, uniformity of test procedures, and control methodologies. By 1922, several states had passed laws and regulations in attempt to prevent introduction of the disease in cattle purchased from other states.

In 1930, the name of the disease was changed from bovine infectious abortion to Bang's disease. Concerns were growing about the relationships between the disease in animals and humans. A committee of the American Veterinary Medical Association recommended a field trial of a vaccine which was developed from a strain of lower virulence named $B$. abortus strain 19. This vaccine has been used for decades as the premier immunizing agent for control of bovine brucellosis. It has been studied in a variety of doses and administration methods.

In 1934, a cooperative State Federal Brucellosis Eradication program was launched on a nationwide scale as part of an emergency cattle reduction program. A uniform plan provided for blood test, slaughter of seropositive cattle, and federal indemnities. Many problems arose including standardization of test procedures. In 1941, strain 19 was introduced and used in most states. All vaccinated cattle were to be properly identified. Vaccination of adult cattle with retention of reactor cattle was permitted in many infected herds.

The lack of funds and personnel during WWII curtailed efforts to control the disease. In 1942, North Carolina became the first state to qualify with a status based upon seroprevalence and in the same year it was recommended that brucellosis be added to the official nomenclature.

In 1947, the Uniform Methods and Rules were introduced and in 1952, the milk ring test was made as a part of the program. It remains the primary method of surveillance on possible brucellosis among dairy cattle herds. In 1960, the Marketed Cattle Program which collects and performs tests on blood of marketed cattle became an extensive part of procedures in most states. Specially trained epidemiologists were being assigned on "problem herds". On several occasions, goals were announced for completion of program and which proved to be unrealistic. Doubts and misgivings about the program emerged many program changes.

Of further veterinary interests, in 1953, Buddle and Boyes in Australia and New Zealand identified B. ovis as a cause of epididymitis in sheep. Later, Carmichael isolated B. canis from aborted canine fetuses.

\section{STATUS IN BANGLADESH}

Before 1945, the India and Bangladesh was the same country and brucellosis was first recognized in India in 1942 (Renukaradhya et al., 2002). So, historically, in this Indian subcontinent, the credit of first investigation of contagious abortion in livestock, associated with brucellosis, goes to the Imperial Veterinary Research Institute (now Indian Imperial Veterinary Research Institute), Muketswar, in northern India (Anonymyous, 1918). In Bangladesh (former East Pakistan) brucellosis was first investigated in 1967 (Mia and Islam, 1967).

It was reported by Mia and Islam (1967) that 37\% of our adult cows were infertile and that bovine infertility causes an economic loss of 40.46 crores of rupees in East Pakistan (Now Bangladesh). It was very probable that brucellosis plays an important role in causing infertility in Bangladesh. 
According a study was conducted by Rahman and Mia (1970) and incidence (18.4\%) of brucellosis was studied in Bangladesh Agricultural University Dairy Farm and in surrounding areas on the basis of tube agglutination test. Later on human, caprine and bovine brucellosis was identified in Bangladesh (Rahman et al., 1983; Amin et al., 2005)

Rahman et al. (1978) reported positive reactions to the Brucella milk ring test (MRT) $11.44 \%$ in Savar, 16.66\% from Tangail and 4.19\% from Bangladesh Agricultural University (BAU) dairy farm. Higher incidence of disease was observed among cows of organized farms.

Rahman and Rahman (1981) studied the incidence of Brucella infection in subclinical mastitic udder, collecting milk samples from the dairy farm at BAU, Central Breeding and Dairy farm, Savar, Dhaka and domestic holdings of adjacent villages of BAU campus. Card screening test was done for subclinical mastitis and milk ring test for brucellosis. The MRT revealed 5.5, 11.44 and $0.00 \%$ of brucellosis in cattle on BAU dairy farm, Central Breeding and Dairy farm, savar and rural areas respectively. With the help of bacteriological technique, it was possible to isolate and identify Brucella organism from 2\% samples of BAU dairy farm, 3.4\% from Central Breeding and Dairy farm, savar and none from BAU campus adjacent villages.

Pharo et al. (1981) studied the prevalence of bovine brucellosis in the Pabna milk-shed area of Bangladesh. By using Milk Ring test they showed that in individual herd the prevalence was $62.5 \%$, 30.7\% of MRT positive cows were found to be RBPT (rose Bengal plate test) positive.

Rahman and Rahman (1982) carried out a study on the prevalence of brucellosis in cows in organized farms and domestic holdings in Bangladesh. It was observed that $11.52 \%$ of a total of 425 milk samples from cows belonging to Baghabari milk shed area, Pabna, $2.92 \%$ of 3.6 milk samples of Takerhat, Faridpur, and $2 \%$ milk samples from different villages of Bogra district were positive to MRT. Serological test in order to determine the prevalence of Brucella agglutination in sera samples of MRT positive cows showed that $8.47 \%, 1.63 \%$ and $0.41 \%$ of milk samples from Pabna, Faridpur and Bogra respectively were also positive for RBPT. Higher incidence of disease (about 4\%) was observed among cows of farms particularly in exotic and cross breeds.

Islam et al. (1983) reported that economic losses due to brucellosis among cattle in Bangladesh is due to abortion, loss of calf production, reduced milk yield, infertility, disposal of vectors and also occasional mortality. The total monetary loss from milk, calves was calculated to be Taka 0.88 million per 1000 heads of cows per year. On conservative estimation these amount may be accepted as taka 0.15 million for 1000 cross bred cows and taka 85.00 million for 1000 exotic breed cows.

A study was carried out on sero-prevalence of human and animal brucellosis in Bangladesh by Rahman et al. (1983). Higher occurrence of the brucellosis was observed in cows of organized farms. In addition, the occurrence of Brucella agglutinins in dairy and agricultural workers, who were in direct contact with animals.

Rahman et al. (1988) reported the seroprevaelnce of brucellosis among goats of domestic holding of some selected areas of Bangladesh. Higher incidence of the disease was observed in goats with reproductive disorders. In addition, the occurrence of Brucella agglutination in individuals who were in direct contact with goat population revealed higher occurrence of the disease.

A study was carried out on seroprevalence of brucellosis in indigenous zebu cows of Bangladesh by Ahmed et al. (1992). Serological tests (plate and tube agglutination) of 350 sera samples collected from indigenous zebu cows of Bangladesh were performed to determine the incidence of brucellosis. Although higher incidence of brucellosis was noted in cows from organized farms (5.0\%) than rural cows (2.76 \%), and also in pregnant cows $(3.23 \%)$ than non-pregnant cows $(3.10 \%)$, these differences were not statistically significant $(\mathrm{p}<0.05)$. An incidence of $4.75 \%$ Brucella-positive cases was recorded in cows above 3 years of age whereas it was 0.71 per cent in cows less than 3 years of age. This difference was significant $(p<0.05)$. The highest incidence $(9.09 \%)$ of brucellosis was found in cows with a history of previous abortion.

In 1997, a study was carried out on sero-prevalence of brucellosis in buffalo (Bubalus bubalis) of a selected areas in Bangladesh (Rahman et al., 1997). In general, 6.9\% buffaloes examined were positive to brucellosis at initial screening using PAT. When confirm by TAT only $2.4 \%$ animals showed diagnostic titre of antibody against Brucella abortus in their serum. The proportion of Brucella positive animals was higher in pregnant group (2.1\%) compared with non pregnant ones (2.6\%). The proportion of Brucella positive animals were highest (7.1\%) in the group with history of retained placenta and lowest (1.2\%) in the group of repeat breeders. 
In 2005, a studied the prevalence of Brucella antibodies in sera of cows in Bangladesh (Amin et al., 2005). The study was carried out to investigate the prevalence of Brucella antibodies in sera of 120 cows in Bangladesh Agricultural University Dairy Farm and adjacent villages, Bangladesh. The epidemiological history and blood was collected from the cows. The serum samples were subjected to Rose Bengal Test (RBT) and plate agglutination test (PAT) for initial screening of Brucella antibodies and the positive sera samples were then subjected to tube agglutination test (TAT) for further confirmation. The higher rate of Brucella antibody was recorded in rural farm (5.0\%) than organized farm (2.5\%) and in pregnant cows (5.9\%) than non-pregnant cows (4.7\%). A total of 3(4\%) Brucella positive antibody cases were recorded in cows of above four years of age whereas, $1(2.3 \%)$ positive case was found in cows of less than 4 years of age. The study revealed that number of Red Shindi was the highest and the prevalence of brucellosis in Bangladesh cow population is not negligible and it is worthwhile to consider adoption of preventive measures.

\section{CONCLUSION}

It is important to remember that brucellosis is a true zoonosis and the stimulus for hopeful elimination is primary public health. Nearly every case of human brucellosis has an animal origin and, therefore, control is primarily a veterinary responsibility (Nicoletti, 1992). B. melitensis widely accepted as the most virulent of Brucella spp., has proven to be a very difficult organism to eliminate. Even after more than a century for the first description, no major country has been able to eradicate the disease following its widespread establishment.

The Brucellae are 'survivors' in both extracellular and intracellular environments. Compatible relationships with the hosts including variable incubation periods, asymptomatic carriers and resistance to treatments are among the problems. These and animal husbandry factors such as commerce, nomadism, commingling, and increasing population sizes assure difficulties in control of diseases. The failure to recognize the importance of rapid population immunization procedures has led to important restrictions in vaccine usage. In humans, food habits are very difficult to change which will assure many future cases of foodborne diseases.

Research will surely develop improved diagnostic methods, immunizing agents and treatment regimens. Nevertheless, the intrinsic and extrinsic factors related to animal and human brucellosis and its control will continue to be formidable obstacles in the continuing evolution of the history of brucellosis.

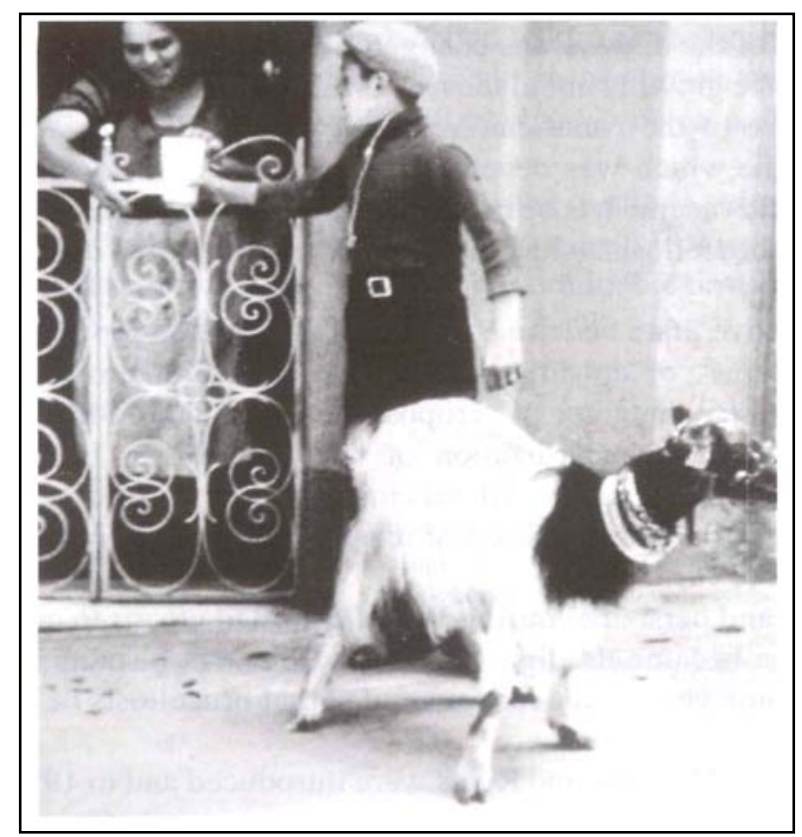

Fig. 1. Fresh milk delivery in Malta (courtesy by E. Young, 1995). 


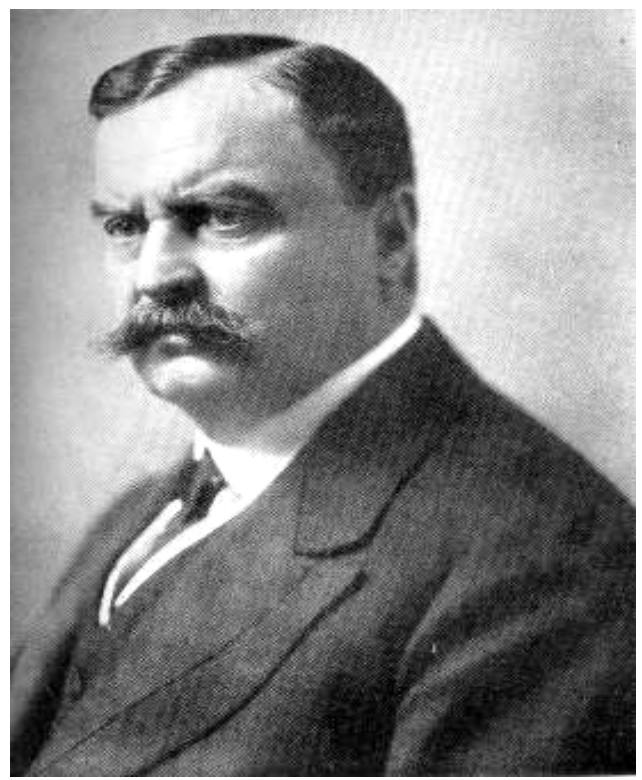

Fig. 2. Sir David Bruce (1853-1910) discovered Malta fever in 1886. He successfully transmitted the disease to monkey and designated it as Mediterranean fever. The disease has been named Brucellosis in honour of his contribution (courtesy by E. Young, 1995).

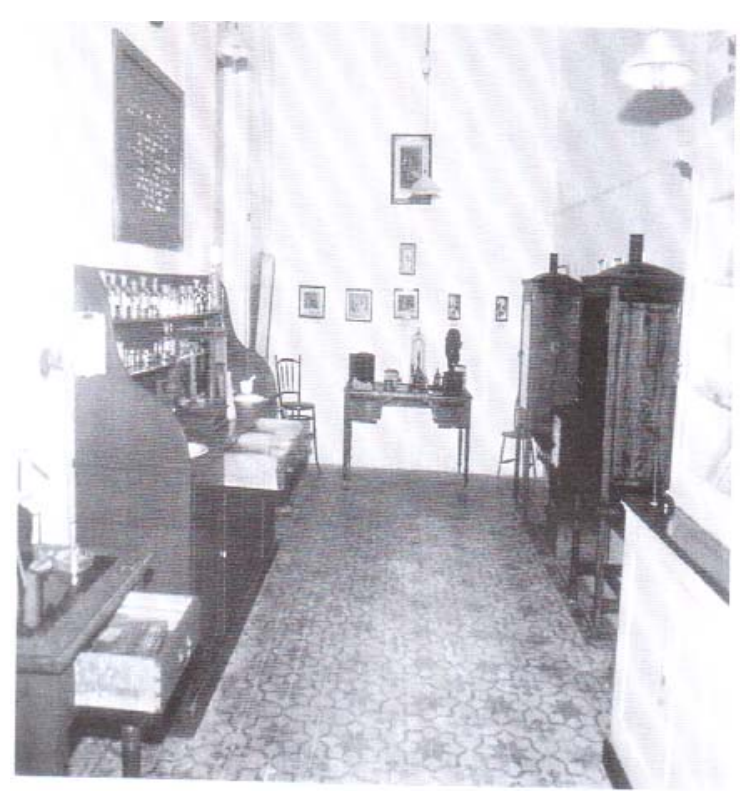

Fig. 3. Restored laboratory of Bruce and others in Malta (courtesy by E. Young, 1995).

\section{REFERENCES}

1. Ahmed JU, Alam MGS, Rahman M M and Hossain M (1992). Seroprevalence of brucellosis in indigenous zebu cows of Bangladesh. Bangladesh Journal of Microbiology 9: 17-21.

2. Amin MRK, Rahman MB, Rahman MS, Han JC, Park JH and Chae JS (2005). A study was carried out on prevalence of Brucella antibodies in sera of cows in Bangladesh. Journal of Veterinary Science 6: 223-226.

3. Anonymous (1918). Annual report, 1917-1918. Imperial Institute of Veterinary Research, Mukteswar, Uttar Pradesh, India, 16.

4. Brown GAL (1977). The history of brucellosis eradication program in the United States. Ann. Sclavo 19.20-34.

5. Hugh-Jones ME (2000). Zoonoses, Recognition, Control and Prevention. Edited by Hugh-Jones ME, Hubbert WT and Hagstad HV; $1^{\text {st }}$ edn., Iowa State Press, A Blackwell Publishing Company.

6. Islam A, Haque M, Rahman A, Rahman MM, Rahman A and Haque F (1983). Economic losses due to brucellosis in cattle in Bangladesh. Bangladesh Veterinary Journal 17: 57-62.

7. Mia AS and Islam H (1967). Preliminary study on the incidence of Bovine Infertility and the Economic loss caused by it. Pakistan Journal of Veterinary Science 1: 5-10.

8. Moore CG and Schnurrenberger PR (1981). A review of naturally occurring Brucella abortus infections in wild mammals. Journal of American Veterinary Medical Association 179: 1105-1112.

9. Nicoletti P (1992). The control of brucellosis--a veterinary responsibility. Saudi Medical Journal 13: 10- 133.

10. OIE (2000). OIE Manual of Standards for Diagnostic Tests and Vaccines. $4^{\text {th }}$ edn., 12 Rue de Prony, 75017 Paris, France.

11. Pharo HJ, Motalib A, ALam S, Fraser GC and Routledge SF (1981). Preliminary information on the prevalence of bovine brucellosis in the pabna milk-shed area of Bangladesh. Bangladesh Veterinary Journal 15: 43-51.

12. Rahamn MM, Haque M and Rahman MA (1988). Seroprevalence of caprine and human brucellosis in some selected areas of Bangladesh. Bangladesh Veterinary Journal 22: 85-92. 
13. Rahman MA, Islam MS, Alam MGS and Shamsuddin M (1997). Sero-prevalence of brucellosis in the buffalo (Bubalus bubalis) of a selected area in Bangladesh. Buffalo Journal 2: 209-214.

14. Rahman MA and Mia AS (1970). A study of brucellosis in Bangladesh. Journal of Agricultural Science 3: 39-44.

15. Rahman MM and Rahman MA (1981). Incidence of Brucella infection in sub-clinical mastitic udder. Bangladesh Veterinary Journal 15: 39-42.

16. Rahman MM and Rahman MS (1982). Study on the prevalence of brucellosis in cows in organized farms and domestic holdings in Bangladesh. Bangladesh Veterinary Journal 16: 53-58.

17. Rahman MM, Chowdhury TIMF and Chowdhury MUA (1978). Investigation of brucellosis among cattle. Bangladesh Veterinary Journal 12: 12-15.

18. Rahman MM, Chowdhury TIMFR, Rahman A and Farida Haque (1983). Seroprevalence of human and animal brucellosis in Bangladesh. Indian Veterinary Journal 60: 165-168.

19. Renukaradhya GJ, Isloor S and Rajashekar M (2002). Epeidemiology, zoonotic aspects, vaccination and control/eradication of brucellosis in India. Veterinary Microbiology 90: 183-195.

20. Vassalo DJ (1992). The corps disease: brucellosis and its historical association with the Royal Army Medical Corps. Journal of Royal Army Medical Corps 138: 148-150.

21. Wyatt FIX (1999). Royal Navy Surgeons and the transmission of brucellosis by goats' milk. Royal Naval Medical Survey 85: 112-117.

22. Young JE (1995). An overview of human brucellosis. Clinical Infectious Diseases 21: 283-290. 